\title{
Healthcare System Stakeholders
}

Hubertus Rosery, Tonio Schönfelder

4.1 State Actors - 92

4.2 Federal Joint Committee -93

4.3 Quality Assurance Initiatives -94

4.3.1 AQUA Institute - 94

4.3.2 Institute for Quality Assurance and Transparency in Healthcare - 95

4.3.3 German Arthroplasty Registry »Endoprothesenregister Deutschland« -95

4.3.4 endoCert -96

4.3.5 Project on Quality Assurance of Inpatient Care using Routine Data -97

4.3.6 Quality Assurance Measures in Rehabilitation - 98

4.3.7 Review of Orthopedics and Trauma Surgery Research -98

4.4 Medical Societies and Professional Associations - 99

4.5 Patient Support and Advice - 100

4.6 The German Medical Technology Association (BVMed) - 101

4.7 Training and Further Education of Healthcare Staff - 101

4.7.1 Basic and Specialty Training of physicians - 101

4.7.2 Training and Continuing Education for Nursing Staff - 102 References -102 


\section{Summary}

In order for a medical device to be marketable in Europe it must bear the CE mark. CE certification is granted if the device conforms to specific safety and performance requirements. Monitoring is conducted by so-called »Notified Bodies«. Manufacturers can select any one of these certification bodies to certify a medical device. In Germany, the certification procedure for endoprostheses is regulated in the Medical Device Directive 93/42/EEC and is implemented through the Medical Devices Act and further decrees. Up to now, the AQUA Institute for Quality Improvement and Research in the Healthcare System (AQUAInstitut für angewandte Qualitätsförderung und Forschung im Gesundheitswesen) has been responsible for external inpatient quality assurance which is mandatory in Germany. The institute publishes detailed reports concerning the quality outcomes of patient care, which both hospitals and patients can use for comparisons with other establishments. As of 2016, the Institute for Quality Assurance and Transparency in the Healthcare System (Institut für Qualitätssicherung und Transparenz im Gesundheitswesen (IQTiG)), which was founded by the Federal Joint Committee, has assumed this responsibility. The German arthroplasty registry »Endoprosthenregister Deutschland « was initiated in 2013 and aims to document quality outcomes of knee and hip arthroplasty across Germany. The purpose of the registry is to enable the tracking of typical service lives of implants used and to investigate reasons for undesired treatment outcomes. The validity of the registry is still limited as about only half of the hospitals that perform arthroplasty currently contribute to it and only a limited number of primary hip and knee arthroplasties are recorded.

EndoCert is a certification system that was established by the German Society of Orthopedics and Orthopedic Surgery (Deutsche Gesellschaft für Orthopädie und Orthopädische Chirurgie (DGOOC)) and the German arthroplasty association »Deutsche Gesellschaft für Endoprothetik (AE)« and the Professional Association of Orthopaedic Surgeons (Berufsverband der Fachärzte für Orthopädie und Unfallchirurgie e. V. (BVOU)).

Initial results show a decline in complication rates and an improvement in outcome quality amongst a few certified institutions.
Alongside representing the interests of their members and offering basic and specialty training, medical societies also assume an important role with regard to research and towards improving the quality of healthcare. The trauma registry »TraumaRegister of the German Society for Trauma Surgery (Deutsche Gesellschaft für Unfallchirurgie (DGU)) « is affiliated with hospitals specializing in trauma surgery and aims to evaluate the effectiveness of methods used in medical treatment. The German arthroplasty association »Deutsche Gesellschaft für Endoprothetik $(A E)$ « is a division of the German Society for Orthopaedics and Trauma (Deutsche Gesellschaft für Orthopädie und Unfallchirurgie (DGOU)) and is involved in quality assurance of endoprosthetic care and in the development of new technologies.

\subsection{State Actors}

In order for a medical device to be marketable in Europe it must bear the CE mark. CE mark certification can be obtained if the device conforms to specific safety and performance requirements. Medical devices are categorized into four classes (I, IIa, IIb, III) in addition to active implants. The classification is based on the potential safety risk that the medical device bears when it is used. A walking aid (class I) is categorized in a lower class than a dental implant (class IIb) or a hip implant (class III). The medical device's class determines the types of conformity assessments that are to be conducted. Hip and knee endoprostheses are class III devices and are therefore subject to stringent testing (BMG 2010).

Conformity assessment procedures are conducted by so-called "Notified Bodies «. As of November 2015, 62 Notified Bodies have been operating in Europe of which 13 are based in Germany (European Commission 2015). Endoprosthesis manufacturers are free to choose any Notified Body that has been notified to certify their products in a particular device category. Notified Bodies are state-accredited and state-monitored. An expert group for certification bodies from the Central $\mathrm{Au}$ thority of the Länder for Health Protection with regard to Medicinal Products and Medical Devices (Zentralstelle der Länder für Gesundheitsschutz bei 
Arzneimitteln und Medizinprodukten (ZLG)) is responsible for notifying and monitoring the certification bodies as stipulated by the Medical Devices Act.

Devices bearing the CE mark are available on the market for a limited period only. After five years at most the quality management systems of both the manufacturer and the devices must be recertified according to $₫ 11$ section 11 of the Medical Device Directive (MDD). Following an initial certification, annual audits are conducted by the Notified Bodies. In addition, the Notified Bodies conduct spontaneous audits of the manufacturers and their major suppliers (European Union 2013).

The certification procedure for endoprostheses is standardized and regulated by the Medical Device Directive 93/42/EEC which is implemented in Germany through the Medical Devices Act and other decrees. Endoprostheses that have been granted the CE mark according to the Medical Devices Act are marketable across the 31 member states of the European Economic Area.

According to $\$ 15$ of the Medical Devices Act, the Federal Ministry of Health (Bundesministerium für Gesundheit (BMG)) must inform the Federal Ministry for Economic Affairs and Energy (Bundesministerium für Wirtschaft und Energie (BMWi)) of which bodies have been notified by the ZLG and what their assigned responsibilities are. Subsequently, the BMWi informs the European Commission. Beyond this, the BMG has various responsibilities which directly and indirectly affect the field of arthroplasty. These include establishing regulations for medical rehabilitation and developing frameworks for monitoring medical devices.

The Federal Institute for Drugs and Medical Devices (Bundesinstitut für Arzneimittel und Medizinprodukte (BfArM)) is an independent federal authority within the Federal Ministry of Health portfolio and is both directly and indirectly involved in the field of arthroplasty. Responsibilities of the BfArM with regard to medical devices include centralizing recording, evaluating and assessing risks and coordinating relevant corrective measures that subsequently need to be taken (BfArM 2013).

The BMG also assumes a supervisory role in the healthcare system's joint self-governing structure. The Federal Joint Committee (Gemeinsamer Bun- desausschuss (G-BA)) is the highest decision-making body for this structure.

\subsection{Federal Joint Committee}

The Federal Joint Committee (G-BA) is the highest decision-making body of the joint self-government consisting of healthcare providers and payers in Germany. The G-BA decides which services are covered by statutory health insurance (SHI) as well as which quality assurance measures are employed in patient care (G-BA 2015a).

External quality assurance within hospitals is regulated by $\$ 137$ Volume V of the German Social Security Code. The G-BA has commissioned the AQUA Institute for Applied Quality Improvement and Research in Health Care (AQUA-Institut für angewandte Qualitätsförderung und Forschung im Gesundheitswesen $\mathrm{GmbH}$ ) for the supervision and implementation of external inpatient quality assurance (Section 4.3.1). Annual publications on external quality assurance for the years from 2009 to 2015, which also exist for THA and TKA amongst other procedures, are available on the AQUA Institute website (http://www.sqg.de, accessed: 24 February 2016). According to $₫ 137 \mathrm{a}$ Volume $\mathrm{V}$ of the German Social Security Code, the G-BA is responsible for the founding of the Institute for Quality Assurance and Transparency in Healthcare (Institut für Qualitätssicherung und Transparenz im Gesundheitswesen (IQTiG)) as an independent scientific institute. Since 2016, the IQTiG has assumed the role of the AQUA Institute's quality assurance tasks with regard to endoprosthetics (Section 4.3.2).

Since 2005, hospitals in Germany which have been approved to treat statutory health insurance patients are obliged to publish structured quality reports online. Amongst other details, these reports include case numbers for individual indications and operations that a hospital has performed. In addition, the hospitals are obliged to publish some of the outcomes of the surveyed indicators for external inpatient quality assurance purposes. Patients can therefore obtain information about the procedures a hospital is specialized in and check the measurable quality outcomes (quality indicators) before undergoing treatment. However, as these reports only con- 
tain past outcomes, they can only give a reference and do not cover all potential quality indicators (GBA 2014b). Since 2013, a G-BA reference database provides access to overall German hospital quality reports. Information from these reports can be accessed with hospital search engines providing further details on individual quality aspects that have not been included in the above mentioned reports. The database can be accessed through the following website: http://www.g-ba-qualitaets-berichte.de/ (accessed: 22/12/2015) (G-BA 2015b). The G-BA introduced a regulation with regard to the annual number of total knee arthroplasties which is set at a minimum of 50 procedures per hospital (site) per year. This means that hospitals may only provide these services on behalf of the SHI if they expect to perform at least 50 TKAs per year (G-BA 2014a). This regulation is based on study data for hip and knee endoprosthetics which show a predominantly positive connection between case numbers and treatment outcomes (Haas et al. 2013, Lau et al. 2012, Schräder and Ewerbeck 2007, Zenk et al. 2014).

The minimum volume regulation includes the following procedures (G-BA 2014a):

- 5-822.9** custom-made prosthesis,

- 5-822.g** bicondylar surface prosthesis,

- 5-822. $\mathrm{h}^{\star \star}$ femoral and tibial stem prosthesis,

- 5-822.j ${ }^{* *}$ endoprosthesis with enhanced flexion,

- 5-822.k* bicompartmental partial joint prosthesis.

However, there are exceptional budgets which allow a hospital to perform TKAs and be reimbursed by the SHI even if it has not reached the limit of 50 operations per year. An example of this is emergency surgery (G-BA 2014a). An analysis of data from German hospital quality reports from 2004 to 2010 concluded that despite the introduction of minimum volumes, case numbers which were previously below the specified limit have not been in decline. This also applies to TKA. According to the evaluation, this was the case for approximately $8 \%$ of hospitals performing primary TKA $(n=81)$ and $1 \%$ of all cases $(n=2,048)$ in 2010. 19 hospitals did not indicate any relevant exceptional budgets in their quality reports. In contrast, the analysis shows a sharp increase in the number of hospitals that were just below the minimum volume threshold and that had increased their case number to precisely the threshold value (de Cruppé et al. 2014). According to the so-called »TKA transparency list of the federal associations of the health insurance funds and the Federation of Private Health Insurance Funds«, 808 German hospitals met the minimum number requirement for TKA in 2011 (vdek 2011). This is markedly lower than the number of hospitals that performed primary TKA in 2011.

It should be noted that the minimum volume regulation applies to primary total arthroplasty. Unicondylar prostheses replacement and revision total arthroplasty which are technically more demanding are not governed by this regulation. This can lead to distortions in service provision as hospitals increasingly perform total arthroplasty in order to meet the minimum number requirements. Consequently, fewer unicondylar sledge prostheses are implanted, even though this procedure is less harsh on the bones.

\subsection{Quality Assurance Initiatives}

\subsubsection{AQUA Institute}

The AQUA Institute was commissioned to supervise and implement external quality assurance for inpatient care. For distinct medical procedures such as THA and TKA (primary and revision surgery), treatments in all hospitals in Germany are documented according to certain quality indicators. The data are recorded, prepared and evaluated by quality offices at state level (LQS) and by the AQUA Institute (up until 2015). Comparative feedback on the outcomes is provided to the hospitals. If individual hospitals show irregular outcomes, the LQS conduct a so-called "structured dialogue « with the hospitals in order to initiate measures towards improving quality.

The AQUA Institute has made comprehensive and detailed quality reports available concerning the outcomes of patient care in hip and knee endoprosthetics, which is an important aspect in the debate regarding quality of care in this particular field of healthcare.

External hospital quality assurance publications for endoprosthetics are available on the internet at: www.sqg.de in the following areas: 
- primary total hip arthroplasty,

- revision total hip arthroplasty and component revision,

- primary total knee arthroplasty,

- revision total knee arthroplasty and component revision.

The web page lists the national evaluations and descriptions of quality indicators for the period from 2009 to 2014. As of 2016, the newly founded IQTiG has assumed the AQUA Institute's role in the field of endoprosthetics.

\subsubsection{Institute for Quality Assurance and Transparency in Healthcare}

The Institute for Quality Assurance and Transparency in Healthcare (IQTiG) was founded in early 2015 by partners in the joint self-governing structure of the healthcare system and the BMG (IQTiG 2015). On behalf of the G-BA, it is to develop measures for quality assurance and present quality of care criteria in the healthcare system and take part in their implementation (IQTiG 2015). The IQTiG focuses mainly on cross-sectoral quality assurance and developing evaluation criteria for certificates and quality seals. The IQTiG evaluation results are to be published transparently and presented in a manner that is understandable by the general public (IQTiG 2015).

\subsubsection{German Arthroplasty Registry "Endoprothesenregister Deutschland"}

The German arthroplasty registry »Endoprothesenregister Deutschland (EPRD)«(EPRD 2015a) aims to document quality outcomes of knee and hip arthroplasty across Germany (EPRD 2015b). To this end, routine hospital accounting data and pseudonymized patient data from the health insurances (for example, underlying diseases) are analyzed together with the manufacturers « data of the implanted prosthesis components. A product database was established in order to identify prostheses components. It currently lists approximately 45,000 items and is continuously being updated. The data are stored for over a period of 30 years (EPRD 2015b).

The aim of the registry is to enable tracking of individual implant components, to determine typical service lives of a product and to investigate reasons for undesired treatment outcomes which are not always due to the implant. Patients can therefore be kept informed if they are potentially affected by outcome abnormalities. In addition, the registry enables the analyses of data at a hospital level, taking into account not only information about the implant itself but also aspects of inpatient care and patient-related factors. Physicians, hospitals, endoprosthesis manufacturers and health insurance funds are informed of the results serving as a basis for the further development of quality assurance measures (EPRD 2015b, Hassenpflug and Liebs 2014).

Establishment of the registry was initiated by the German Association for Orthopaedics and Orthopaedic Surgery (DGOOC), the AOK Federal Association, the Association of Substitute Health Insurance Funds (vdek), the BQS Institute for Quality and Patient Safety (BQS) and the prostheses manufacturers represented by The German Medical Technology Association (BVMed) (EPRD 2015a, b). The registry is managed by "Deutsche Endoprothesenregister EPRD gGmbH«, a DGOOC subsidiary (EPRD 2015a). It is financed by participating health insurance funds, hospitals and by the industry. According to its own statements, the registry is exclusively committed to scientific principles and guarantees the independent and neutral evaluation of documented data (EPRD 2015b).

The EPRD was initiated in Germany in 2011 and following a probation phase was introduced nationally in 2013. Hospitals that perform arthroplasty can contribute to the EPRD (EPRD 2015b). Arthroplasty registries were introduced in other countries much earlier than in Germany. In Sweden, for instance, knee arthroplasty registries were introduced in 1975 and hip arthroplasty registries in 1979 (Kärrholm 2010, Knutson and Robertsson 2010). Various studies have demonstrated significant decreases in the rates of complications and in the necessity of revision replacements following the introduction of these registries (Herberts and Malchau 2000, Malchau et al. 2005, Swedish Knee Arthroplasty Register (Hrsg.) 2014). Other arthro- 
plasty registries exist in Norway, Finland, Denmark, England, Canada, Australia and New Zealand (Hassenpflug and Liebs 2014).

The EPRD's 2015 status report largely presents descriptive data on primary hip and knee arthroplasty and revision arthroplasty according to patient age and gender. The most common reason for revision total hip and knee replacement is implant loosening (hip: $46.7 \%$, knee: $39.4 \%$ ) followed by infections (hip: $10 \%$, knee: $13.9 \%$ ). Implant component failure accounted for of $3.3 \%$ of all revision total hip arthroplasties and $2.9 \%$ of revision total knee arthroplasties. Determining implant service life based on the data is not yet possible as the majority of patients undergoing revisions underwent primary surgery before they were recorded in the EPRD (EPRD 2015b).

Significant and reliable results can only be achieved through high rates of participation in the registry (Hassenpflug and Liebs 2014). According to February 2016 figures, 684 out of 1,200 hospitals that performed arthroplasty participated in the registry. In 2015, over 140,000 endoprosthetic hip and knee replacements were documented (EPRD 2016).

Participation in the registry and the quantity of data submitted therein is voluntary. Data on implants and surgery are only recorded after a patient has given his/her consent in writing following which participating hospitals can decide whether they document the data for all affected patients or not (EPRD 2015b). Given that the recording of such data is not mandatory, there is the risk of considerable data loss or having only partially documented data in the registry. This may lead to data biases in that the actual quality of treatment may not be fully depicted through the registry. When interpreting the registry evaluations, one must take into account the fact that the represented population consists of patients insured by the statutory health insurance AOK and the Association of Substitute Health Insurance Funds »vdek" (EPRD 2015b). The source population consequently represents approximately two thirds of the insurees from statutory and private health insurances in Germany (BMG 2015). Potential differences amongst those insured by the health insurance funds and insurance companies can influence the validity of the outcomes of the analysis of the registry.

\subsection{4 endoCert}

endoCert is an initiative and a certification system for centers that perform knee and hip arthroplasty. The initiative was started by the DGOOC with the support of the German association for arthroplasty »Deutsche Gesellschaft für Endoprothetik (AE)« of the German Society for Orthopaedics and Trauma (DGOU) and the Professional Association of Orthopaedic Surgeons (BVOU) ( Section 4.4).

endoCert aims to develop and assure quality of treatment through the certification of medical centers based on up-to-date scientific insights and on its experience through the establishment of medical centers in other fields. At present, this certification concept is limited to elective arthroplasty (Haas et al. 2013). General criteria for the certification process are presented in $\bullet$ Fig. 4.1.

Medical centers are required to provide documentation that cover structural quality (e.g. equipment, staff qualification), process quality (e.g. standardized treatment pathways) and outcome quality (patient-reported results, e.g. satisfaction and objective outcomes).

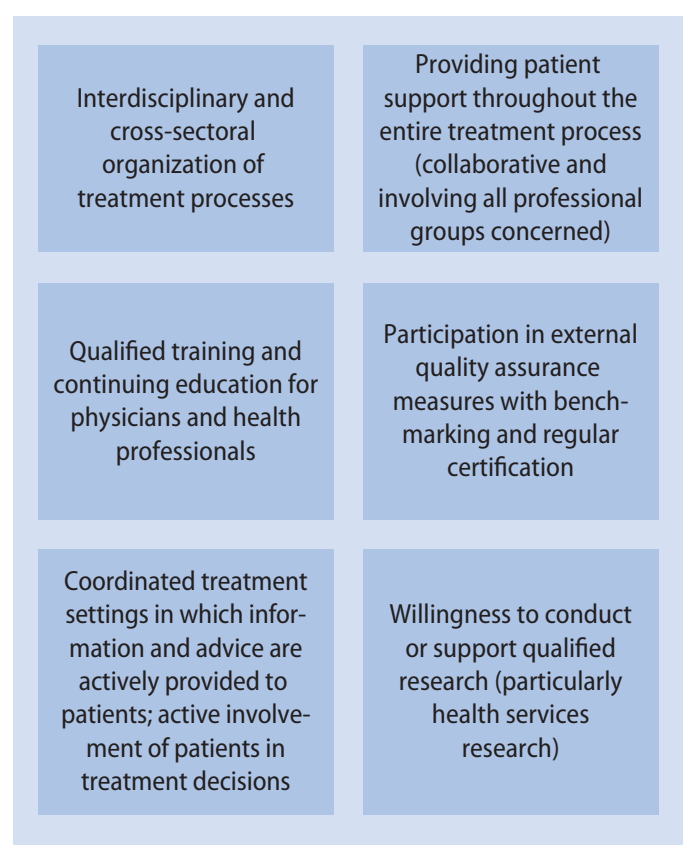

- Fig. 4.1 General criteria for the endoCert certification process. (Source: IGES - Haas et al. 2013) 
The minimum case volume thresholds for arthroplasty for different centers are listed below. However, the initiative emphasizes that these are not recommendations for legal minimum volume regulations:

- Arthroplasty center: At least two main surgeons who each perform at least 50 THAs and/ or TKAs per year (on their own or as responsible assistants)

- Arthroplasty center providing comprehensive care: At least two main senior surgeons who each perform at least 100 THAs and/or TKAs per year, including revision total arthroplasty surgery

This results in a link between minimum case numbers for surgeons and minimum case numbers for arthroplasty centers (at least 100 per year) and arthroplasty centers providing comprehensive care (at least 200 per year).

Centers that would like to attain certification must provide evidence showing that they conform to the quality requirements at all levels (establishment, structures, processes, outcomes). After an application has been submitted, assessed and any further questions and outstanding issues have been clarified an on-site audit is conducted. The center is subsequently granted a period of time in order to rectify any shortfalls. Certifications are limited to a duration of 3.5 years. Besides the initial audit, additional supervisory audits are conducted and the center is audited again once the certification has expired. If the center no longer fulfills the given requirements at this time, the certification can be suspended or, in the worst case, revoked (Haas et al. 2013).

The endoCert website (www.endocert.de) lists 471 certified treatment centers in Germany (as determined on 24 February 2016). Some endoprosthetics centers (comprehensive care) have reported a reduction in complication rates and improvements in quality of outcomes after implementation of the certification (Lewinski et al. 2015). Attaining certification works as an incentive for the centers as they can demonstrate a high level of quality of care to the general public and their (potential) patients and also improve treatment outcomes allowing them to attain good benchmarking levels and external inpatient quality assurance results.
However, at present it is expected that the longterm effects of endoCert on treatment outcomes (complications, service lives) can only be evaluated in combination with the EPRD (Section 4.3.3). Hospitals that participate in endoCert are also obliged to participate in the EPRD (Haas u. Mittelmeier 2014).

\subsubsection{Project on Quality Assurance of Inpatient Care using Routine Data}

In 2002, the quality assurance initiative for inpatient care using routine data »Qualitätssicherung der stationären Versorgung mit Routinedaten (QSR) « was started as a joint research project between the AOK Federal Association, HELIOS Kliniken, the research and development institute for social affairs and the healthcare system in Saxony-Anhalt »Forschungsund Entwicklungsinstitut für das Sozial- und Gesundheitswesen Sachsen-Anhalt (FEISA) « and the AOK Research Institute (Wissenschaftliches Institut der AOK (WidO)). The project aimed to »review the possibilities of measuring quality on the basis of SHI routine data " and specific quality indicators were developed to this end (WiDO 2007).

Information on hospital stays is obtained from routine data, in the same way as for statutory external hospital quality assurance data collection. The main difference with regard to statutory quality assurance measures and an advantage of the project is that several episodes within the chain of a patient's treatment can be combined to obtain longer-term treatment outcomes. This is made possible through data from AOK insurees. The major limitations of this approach are that the data pool is restricted to AOK insuree data only, the characteristics of which differ to those of the general population, in addition to the fact that the data used for the quality analysis were collected for other purposes and hence only permit limited observations concerning the quality of treatment (Jeschke et al. 2013). 


\subsubsection{Quality Assurance Measures in Rehabilitation}

Quality assurance measures are also conducted for rehabilitation treatment. Ambulatory and inpatient rehabilitation institutions with care contracts (according to $\$ 111,111$ a or 111 c section 1 Volume V of the German Social Security Code) are to conduct external quality assurance measures according to $\$$ 137d Volume V of the German Social Security Code. In addition, legal regulations exist for establishing internal quality measures within the institutions according to $\$ 135 \mathrm{a}$ section 2 Volume V of the German Social Security Code. The Federal Association of the Statutory Health Insurance Funds (GKV-Spitzenverband) agrees upon the external quality measures with »the major care provider organizations « according to $\$ 137 \mathrm{~d}$ Volume V of the German Social Security Code. The agreement specifies that the QSReha ${ }^{\circledR}$ procedure be the measure (GKV Spitzenverband (Hrsg.) 2008).

QS-Reha ${ }^{\circledR}$ takes into account structural quality, process and outcome qualities as well as patient satisfaction. According to data currently available, approximately 300 specialist institutions participate in QS-Reha ${ }^{\circledR}$. They are listed on the website (http:// www.qs-reha.de/; accessed: 24 February 2016). The group of "musculoskeletal diseases " is included as an indicator. In 2011, the BQS Institute won the tender to evaluate quality assurance measures. Outcomes from individual institutions are compared with those in the same indication area in order to obtain comparative quality outcomes and average outcomes. The procedure has not yet been fully established. Ambulatory rehabilitation facilities for musculoskeletal diseases (and other areas) have only been included in the procedure during the currently ongoing three-year data collection period from 2015 to 2017 (QS-Reha 2015).

The German Statutory Pension Insurance also conducts comprehensive quality assurance measures in the fields of structural quality as well as process and outcome quality. The procedures include (Deutsche Rentenversicherung 2015):

- surveys of the structural quality of rehabilitation institutions,

- patient interviews to determine patient satisfaction with rehabilitation measures and to obtain patient evaluations on the success of treatment,

- assessments of individual rehabilitation processes by experienced rehabilitation staff,

- documentation of the range of therapeutic services provided by the rehabilitation institutions,

- developing rehabilitation guidelines for the structuring of rehabilitation measures.

These measures also cover THA and TKA. Rehabilitation establishments are issued so-called »Reports on the quality assurance of rehabilitation « which provide feedback about how they conform to the above-mentioned rehabilitation therapy standards and to enable comparisons with other institutions. Therapy standards are divided into modules that enable targeted improvements if any shortfalls are identified (Deutsche Rentenversicherung Bund 2011). Systematic publications of quality assurance outcomes do not exist but overall results, for example with regard to patient satisfaction, may be included in other publications (Deutsche Rentenversicherung Bund 2013). In addition, assessments of patient discharge reports are conducted by experienced physicians in so-called peer reviews. Checklists for rehabilitation procedures, processes and indication-specific requirements are used for these reviews (Baumgarten and Klosterhuis 2007).

\subsubsection{Review of Orthopedics and Trauma Surgery Research}

Diseases of the musculoskeletal system are amongst the most common diseases in Germany. In 2013, these diseases accounted for 313 days of incapacity to work per 100 insuree years with which diseases of the musculoskeletal system were more frequent than any other type of disease (DAK 2014). Osteoarthritis is one of the most common joint diseases in adults worldwide. It is characterized by degenerative diseases of the joints caused by wear and tear of the articular cartilage. Large joints such as the hip (osteoarthritis of the hip) and knees (osteoarthritis of the knee) are most commonly affected. In Germany, arthrosis of the hip or knee joint affects approximately $28 \%$ of women and approximately $20 \%$ of 
men (lifetime prevalence) ( $\triangleright$ Chapter 1$)$. Arthroplasty has become an established procedure for treating these joint diseases (Mittelmeier et al. 2012).

The DGOU surveyed the increasing prevalence of musculoskeletal diseases in relation to demographic trends, current therapeutic measures and the need for further research. The results of this survey were published in a 2012 White Paper: Research in Orthopedics and Trauma Surgery - Review and Outlook (Weißbuch »Forschung in Orthopädie und Unfallchirurgie - Bestandsaufnahme und Ausblick«)«. The White Paper contains detailed information about fundamental research, current research activities and future perspectives with regard to musculoskeletal research (Mittelmeier et al. 2012).

Due to demographic trends and the increasing number of younger patients being treated, it can be expected that the numbers of hip and knee arthroplasties will rise in the future (Ewerbeck et al. 2012). External quality assurance in the field of endoprosthetics in Germany focuses on short-term outcome quality documented up to the point of patient discharge (Liebs and Hassenpflug 2012). Long-term outcome quality is currently not being systematically measured and the effects of different determinants on outcome quality are unknown. It is still currently unclear how long-term outcome quality could be measured precisely (service life, health-related quality of life, patient satisfaction) and how it is affected by surgical procedures, implants, follow-up care and individual patient characteristics (Liebs and Hassenpflug 2012). According to the authors of the White Paper, maintaining an endoprostheses registry could be one way of measuring and evaluating patient data with regard to long-term quality as this has been shown to contribute to significant improvements in the quality of care in other countries (Liebs and Hassenpflug 2012). Such a registry was introduced into German hospitals in 2013 (Section 4.3.3).

Comparative sustainability testing for safe and low-risk medical devices is another objective that has been identified for future research (Mittelmeier et al. 2012). Simulations are to play a greater role in the testing of implants in the future. New implants are to undergo endurance testing by means of modern computer simulations and robot tests before they are approved (Mittelmeier et al. 2012).

Further research in the future is to focus on physiological, biological, biomechanical mechanisms of action and their interactions with the aim of developing new materials and bioactive coatings. Past research has contributed to developing specific types of synthetic materials that reduce implant abrasion and consequently improve patient care (Ewerbeck et al. 2012).

\subsection{Medical Societies and Professio- nal Associations}

The German Society of Orthopedics and Orthopedic Surgery (DGOOC, Deutsche Gesellschaft für Orthopädie und Orthopädische Chirurgie) is dedicated to promoting orthopedics and represents the interests of approximately 3,000 members (DGOU 2013). Besides providing continuing education and specialty training programs in orthopedics, the DGOOC is involved in developing evidence-based guidelines in collaboration with other medical societies. Various DGOOC divisions are responsible for the improvement in different orthopedic sub-specialties. Each division may found its own non-profit association as, for example, the rheumatic orthopedics division has done with the creation of the association »Deutsche Gesellschaft für orthopädische Rheumatologie e.V « (DGORh 2015, DGOU 2013). Working groups within the DGOOC deal with specific scientific subject areas. Currently, there are 17 working groups, including the German joint registry (EPRD) working group (DGOOC 2015). The DGOOC established the EPRD (Section 4.3.3) as a non-profit limited liability company under German law as a wholly-owned subsidiary.

The German Society for Trauma Surgery (DGU, Deutsche Gesellschaft für Unfallchirurgie) was founded in 1922 and includes approximately 4,600 members. The DGU is committed to providing basic and specialty training as well as continuing education in orthopedics and trauma surgery. It publishes guidelines for trauma surgery diagnostics and therapy and plays a major role in quality assurance and improvement of treatment for severely injured 
patients (DGU 2015b). The DGU trauma registry »TraumaRegister $\mathrm{DGU}$ « is an organization made up of trauma surgery specialist hospitals which aims to assess the quality of care and evaluate medical treatment methods with regard to their effectiveness. Over 100,000 datasets from severely injured patients are currently documented in the Trauma Register DGU (DGU 2015a). The DGU trauma network »TraumaNetzwerk DGU« aims to establish nationwide networks for interdisciplinary care of severely injured patients and consequently optimize treatment (DGU 2015a).

The German Society for Orthopaedics and Trauma (DGOU, Deutsche Gesellschaft für Orthopädie und Unfallchirurgie) represents the interests of its two funding bodies, the DGOOC and DGU in orthopedics and trauma surgery. The DGOU was founded in 2008 as a non-profit association and currently includes approximately 10,000 members. Responsibilities of the DGOU include basic and specialty training, continuing education, promotion of research in orthopedics and trauma surgery, making networks and platforms available for scientific exchange and enabling the communication of research results through different scientific journals (DGU 2015b).

The German arthroplasty association »Deutsche Gesellschaft für Endoprothetik e. V. (AE)« is a division of the DGOU dealing with endoprosthetics (DGOU 2015). It was founded in 1996 as a non-profit association with the aim of improving the quality of life of patients with joint diseases and injuries (Deutsche Gesellschaft für Endoprothetik 2014). The AE's main responsibilities include quality assurance and quality control of endoprosthetic care as well as the further development of existing and novel technologies for movement recovery. To this end, the association works closely together with the medical technology industry (Deutsche Gesellschaft für Endoprothetik 2014).

The Professional Association of Orthopaedic Surgeons (BVOU, Berufsverband für Orthopädie und Unfallchirurgie) represents the professional interests of orthopedic and trauma surgery specialists in medical associations and political institutions. The association currently includes approximately 7,000 members (BVOU 2015a). In addition, the BVOU organizes certified advanced and further training in orthopedics, trauma surgery and related subjects in collaboration with the orthopedic academy »Akademie Deutscher Orthopäden« (BVOU 2015b).

Together with the AE and the BVOU, the DGOOC has developed an initiative for certifying medical institutions that offer joint replacement services (endoCert, section 4.3.4).

\subsection{Patient Support and Advice}

The German association for osteoarthritis support "Deutsche Arthrose-Hilfe e.V." is a registered non-profit association which aims to inform people suffering from osteoarthritis about the causes, prevention and treatment of osteoarthritis. It also provides support and counseling in individual cases. The association regularly publishes the »Arthrose-Info" magazine which provides information about the different types of osteoarthritis, their diagnoses and treatment as well as prevention and early detection methods (DAH 2015c).

A further goal is to support scientific and clinical osteoarthritis research (DAH 2015b) for example, by funding research projects and providing grants to young scientists. The association funded the establishment of the EPRD, for example (Section 4.3.3), in addition to a study to measure patient preferences with regard to TKA as well as the in-vivo evaluation of hip implant fixation in THA (DAH 2015a).

The German league against rheumatism "Deutsche Rheuma-Liga" includes 290,000 members and describes itself as the largest self-help organization in the field of healthcare. Its responsibilities include offering support and self-help services to patients, representing the interests of those suffering from rheumatism in politics, healthcare and the public as well as promoting research (Deutsche Rheuma-Liga 2015a). To this end, the Rheuma-Liga collaborates closely with other associations and organizations such as the DGOOC (Deutsche Rheuma-Liga 2015b). It makes comprehensive information available regarding endoprosthetics and facilitates decision-making processes with regard to replacement surgery. Amongst other things, it provides reports on patient experiences, a fact sheet on arthroplasty and information about treatment 
options if an implant is defective (Deutsche Rheuma-Liga 2015c).

The pain forum »Forum Schmerz « is a division of the German Green Cross (Deutsches Grünes Kreuz e. V.) which keeps patients informed on pain therapy options and makes recommendations for various approaches to treatment in collaboration with a scientific advisory board. The forum provides information online (http://www. forum-schmerz.de/schmerz-infos/arthrose.html, last accessed: 22 December 2015) regarding osteoarthritis, its causes, diagnosis, therapies and self-help options (Forum Schmerz 2015).

\subsection{The German Medical Technology Association (BVMed)}

As a trade association, The German Medical Technology Association (BVMed) promotes and represents the interests of the medical technology industry and trade companies in public and informs political decisions (BVMed 2014b). The BVMed currently includes 227 member companies (BVMed 2015a).

The BVMed represents the interests of its members with regard to hip, knee, shoulder and spinal implants, heart valves and defibrillators as well as medical dressings, incontinence products, synthetic disposable items such as catheters and cannulas, homecare services and nanotechnology applications (BVMed 2014a).

The BVMed provides its members with information and advice on legal matters and regulations and establishes platforms for dialogue and exchange through project groups, working groups and sector interest groups. The »Endoprosthetics - Implants« sector interest group is involved in public discussions and works towards informing political decision-makers about the benefits of endoprosthetic care (BVMed 2015a).

\subsection{Training and Further Education of Healthcare Staff}

The outcome of joint replacement surgery is not only determined by factors relating to an individual patient and accompanying diseases but also to medical staff involved in the operation. Studies on hip and knee replacements demonstrate that a surgeon's professional capabilities can influence the rate of complications (Lau et al. 2012, Zenk et al. 2014).

\subsubsection{Basic and Specialty Training of physicians}

As registered organizations under public law in Germany, all State Chambers of Physicians (Landesärztekammer) are responsible for offering further specialist training. The German Medical Association (Bundesärztekammer) develops (model) regulations on specialty training which serve as a recommendation for the State Chambers of Physicians (B̈̈K 2015). In addition to (model) specialty training regulations, (model) guidelines are also given for further training. These guidelines are developed in collaboration with the State Chambers of Physicians and are also based on feedback from medical societies and professional associations. The (model) guidelines stipulate requirements for training in terms of the number of examinations and treatments that must be performed to attain a specific qualification. They also take into account average performance of hospitals and medical practices (BÄK 2011).

Specialty training for orthopedics and the sub-specialty trauma surgery were merged in 2005 (B̈̈K 2015). The goal upon completion of this sixyear specialty training for orthopedics and trauma surgery is for physicians to attain basic and subsequent specialist competence in orthopedics and trauma surgery upon completion of the required training period.

According to the German Medical Association's 2013 model code of continuing professional development, physicians must undergo continuing education in order to maintain and develop their professional expertise. Physicians are required to attain a minimum of 250 additional training credit points within a period of five years. According to Volume $\mathrm{V}$ of the German Social Security Code, statutory health insurance physicians and consultants in working in hospitals are required to provide further evidence of participation in continuing medical education. 
Professional associations (e.g. DGOOC, DGOU) and institutional centers provide part of the further training required. In addition, workshops and seminars held by manufacturers of medical devices also constitute part of the further training (BVMed 2015b). Further training programs have not been systematically evaluated.

Further training and continuing education for physicians and nursing staff plays an important role in establishing integrated comprehensive risk and quality management under endoCert (Haas et al. 2013).

\subsubsection{Training and Continuing Education for Nursing Staff}

Nursing training is regulated by the Nursing Act (Krankenpflegegesetz). Surgical nursing staff firstly work in a surgical unit for at least six months and subsequently complete a two-year vocational training program. Surgical technicians (Operationstechnischer Assistent (OTA)) undergo a three-year training program. OTAs support the surgical team and the patient before, during and after surgery (DOSV 2016). Training content and examination regulations for nursing staff are developed in parallel to those of physicians. Further training events, workshops and seminars held by manufacturers of medical devices manufacturers also constitute part of the training and continuing education for nurses.

Open Access This chapter is published under the Creative Commons Attribution NonCommercial 4.0 International license (http://creativecommons.org/licenses/by-nc/4.0/deed.de) which grants you the right to use, copy, edit, share and reproduce this chapter in any medium and format, provided that you duly mention the original author(s) and the source, include a link to the Creative Commons license and indicate whether you have made any changes.

The Creative Commons license referred to also applies to any illustrations and other third party material unless the legend or the reference to the source states otherwise. If any such third party material is not licensed under the above-mentioned Creative Commons license, any copying, editing or public reproduction is only permitted with the prior approval of the copyright holder or on the basis of the relevant legal regulations.

\section{References}

BÄK (2011): (Muster-)Richtlinien über den Inhalt der Weiterbildung (MWBO 2003) in der Fassung vom 18.02.2011. http://www.bundesaerztekammer.de/fileadmin/user_ upload/downloads/RiliMWBO20110218.pdf [accessed: 08 April 2016].

BÄK (2015): (Muster-) Weiterbildungsordnung 2003 in der Fassung vom 23.10.2015. Bundesärztekammer. http:// www.bundesaerztekammer.de/fileadmin/user_upload/ downloads/pdf-Ordner/Weiterbildung/MWBO.pdf [accessed: 30 January 2016].

Baumgarten E \& Klosterhuis H (2007): Aktuelles aus der Reha-Qualitätssicherung: Peer Review-Verfahren ausgewertet - bessere Reha-Qualität, aber deutliche Unterschiede zwischen Reha-Einrichtungen -. RVaktuell 5, 152-154.

BfArM (2013): Organisation und Aufgaben. Bonn: Bundesinstitut für Arzneimittel und Medizinprodukte,. http:// www.bfarm.de/DE/BfArM/Org/_node.html [accessed: 10 November 2015].
BMG (2010): Marktzugangsvoraussetzungen für Medizinprodukte - Zuständigkeiten in Deutschland: Information correct as of: June 2010 Berlin: Bundesministerium für Gesundheit. http:// www.bmg.bund.de/fileadmin/ dateien/Downloads/M/Medizinprodukte/Medizin_ Produkte_Marktzugangsvoraussetzungen_fuer_Medizinprodukte.pdf [accessed: 10 November 2015].

BMG (2015): Gesetzliche Krankenversicherung - Mitglieder, mitversicherte Angehörige und Krankenstand Jahresdurchschnitt 2014 (Ergebnisse der GKV-Statistik KM1/13). Information correct as of: 19 March 2015. Bundesministerium für Gesundheit.

BVMed (2014a): BVMed-Leistungen. Latest update: 29 March 2014. Berlin. http://www.bvmed.de/de/bvmed/ wir-ueberuns/bvmed-leistungen [accessed: 11 November 2015].

BVMed (2014b): BVMed-Satzung. Latest update: 08 April 2014. Berlin. http://www.bvmed.de/de/bvmed/ wir-ueber-uns/ satzung [accessed: 11 November 2015].

BVMed (2015a): BVMed-Jahresbericht 2014/15. Berlin: BVMed - Bundesverband Medizintechnologie e.V. 
BVMed (2015b): Veranstaltungen. http://www.bvmed.de/de/ bvmed/veranstaltungen [accessed: 11 November 2015].

BVOU (2015a): Über den BVOU. Berlin. http://www.bvou.net/ uber-den-bvou/ [accessed: 11 November 2015].

BVOU (2015b):Werden Sie Mitglied im BVOU. Berlin. http:// www.bvou.net/uber-den-bvou/ [accessed: 11 November 2015].

DAH (2015a): Arthroseforschung hilft. Frankfurt/Main. http:// www.arthrose.de/forschung.html [accessed: 11 November 2015].

DAH (2015b): Aufgaben. Frankfurt/Main. http://www.arthrose. de/verein/aufgaben.html [accessed: 11 November 2015].

DAH (2015c): Information und Aufklärung. Frankfurt/Main. http://www.arthrose.de/information.html [accessed: 11 November 2015].

DAK (2014): DAK-Gesundheitsreport 2014. Hamburg: DAK Forschung.

de Cruppé W, Malik M \& Geraedts M (2014): Umsetzung der Mindestmengenvorgaben: Analyse der Krankenhausqualitätsberichte: Eine retrospektive Studie der Jahre 2004-2010. Deutsches Ärzteblatt 111(33-34), 549-555. DOI: 10.3238/arztebl.2014.0549.

Deutsche Gesellschaft für Endoprothetik (2014): AE - Deutsche Gesellschaft für Endoprothetik e.V. Berlin. http://www. ae-germany.com/index.php?option=com_content\&

view $=$ article\&id=22\&ltemid=153 [accessed: 30 October 2015]

Deutsche Rentenversicherung (2015). http://www. deutsche-rentenversicherung.de/Allgemein/de/Navigation/0_Home/home_node.html [accessed: 10 November 2015].

Deutsche Rentenversicherung Bund (2011): Reha-Therapiestandards Hüft- und Knie-TEP. Leitlinie für die medizinische Rehabilitation der Rentenversicherung. Berlin.

Deutsche Rentenversicherung Bund (2013): Reha-Bericht. Die medizinische und berufl iche Rehabilitation der Rentenversicherung im Licht der Statistik. Berlin. ISSN: 21935718.

Deutsche Rentenversicherung (2015). http://www. deutsche-rentenversicherung.de/Allgemein/de/Navigation/0_Home/home_node.html [accessed: 10 November 2015].

Deutsche Rheuma-Liga (2015a): Eine starke Gemeinschaft. Latest update: 19 June 2015. Bonn. https://www. rheuma-liga.de/verband/ [accessed: 11 November 2015].

Deutsche Rheuma-Liga (2015b): Kooperationspartner. Latest update: 01 July 2015. Bonn. https://www.rheuma-liga.de/ verband/bundesverband/kooperationspartner/ [accessed: 11 November 2015].

Deutsche Rheuma-Liga (2015c): Künstliche Gelenke - Endoprothesen. Bonn. https://www.rheuma-liga.de/gelenkersatz/ [accessed: 11 November 2015].

DGOOC (2015): Gremien der DGOOC. Deutsche Gesellschaft für Orthopädie und Orthopädische Chirurgie http:// www.dgooc.de/gremien [accessed: 10 November 2015].

DGORh (2015): Struktur der DGORh. Deutsche Gesellschaft für Orthopädische Rheumatologie e.V. http://www.rheuma-orthopaedie.de/Die-DGORh.31.0.html [accessed: 10 November 2015].
DGOU (2013): Pressemitteilung DKOU Berlin 22.-25.10.203. Immer mehr junge Patienten mit Endoprothesen Anspruch an künstliche Gelenke wächst. Berlin: Deutscher Kongress für Orthopädie und Unfallchirurgie. http://www.dgou.de/index.php?elD=tx_nawsecuredl\&u $=0 \& \mathrm{~g}=0 \& \mathrm{t}=1446632832 \&$ hash $=5422 \mathrm{~d} 6098211 \mathrm{f} 9605$ c06b4750537cb532c138e3a\&file=uploads / media/ 2013_10_23_PM_DKOU_Endoprothesen.pdf [accessed: 03 November 2015].

DGOU (2015): AE - Deutsche Gesellschaft für Endoprothetik. http://www.dgou.de/gremien/sektionen/endoprothetik. html [accessed: 10 November 2015].

DGU (2015a): TraumaRegister DGU ${ }^{\circledR}$. http://www.dgu-online. de/qualitaet-sicherheit/schwerverletzte/traumaregister-dgur.html [accessed: 10 November 2015].

DGU (2015b): Über uns. http://www.dgu-online.de/ueberuns/ueber-uns.html [accessed: 10 November 2015].

DOSV (2016): DOSV: Hoch qualifizierte Fachkräfte in der OP-Assistenz. http://www.ota.de/das-berufsbild/ [accessed: 08 April 2016].

EPRD (2015a): EPRD Endoprothesenregister Deutschland. Berlin. http://www.eprd.de/ [accessed: 10 November 2015].

EPRD (2015b): Statusbericht 2014: Mit Sicherheit mehr Qualität. Berlin: EPRD Deutsche Endoprothesenregister gGmbH. ISBN: 978-3-9817673-0-8.

EPRD (2016): Pressemitteilung vom 8. Februar 2016. Erstmals am EPRD teilnehmende Kliniken veröffentlicht. Berlin: Deutsche Endoprothesenregister gGmbH. http://www. eprd.de/fileadmin/Dateien/Medien/PM_EPRD/EPRD_PM_ Erstmals_am_EPRD_teilnehmende_Kliniken_veroeffentlicht_final_1_2016_02_08.pdf [accessed: 25 February 2015].

European Union (2013): Commission Recommendation of 24 September 2013 on the audits and assessments performed by notified bodies in the field of medical devices Official Journal of the European Union (2013/473/EU).

European Commission (2015): Bodies. http://ec.europa.eu/ enterprise/newapproach/nando/index.cfm?fuseaction =directive.notifiedbody\&dir_id=13 [accessed: 10 November 2015].

European Society of Cardiology (Hrsg.) (2014): 2014 ESC Guidelines on the diagnosis and management of acute pulmonary embolism. European Heart Journal, 30333080. DOI: 10.1093/eurheartj/ehu283.

Ewerbeck V, Bitsch RG \& Kretzer JP (2012): Endoprothetik primär. In: Deutsche Gesellschaft für Orthopädie und Unfallchirurgie e.V.: Forschung in Orthopädie und Unfallchirgurgie - Bestandsaufnahme und Ausblick. Weißbuch Forschung in Orthopädie und Unfallchirurgie. 152-153. http://www.dgu-online.de/fileadmin/published_content/4.Wissenschaft/PDF/DGOU_Weissbuch_Muskuloskelettale_Forschung_final.pdf.

Forum Schmerz (2015): Wir über uns. Marburg: Deutsches Grünes Kreuz. http://www.forum-schmerz.de/wir.html [accessed: 11 November 2015].

G-BA (2014a): Beschluss des Gemeinsamen Bundesausschusses über eine Invollzugsetzung einer Regelung der Min- 
destmengenregelungen: Mindestmenge für Kniegelenk-Totalendoprothesen. Berlin: Gemeinsamer Bundesausschuss. https://www.g-ba.de/downloads/39-2612131/2014-12-18_Mm-R_Knie-TEP_BAnz.pdf [accessed: 10 November 2015].

G-BA (2014b): Die gesetzlichen Qualitätsberichte 2012 der Krankenhäuser lesen und verstehen. Berlin: Gemeinsamer Bundesausschuss.

G-BA (2015a): Gemeinsamer Bundesausschuss. Latest update: 10 November 2015. Berlin. https://www.g-ba. de/ [accessed: 10 November 2015].

G-BA (2015b): Wo findet man die Qualitätsberichte der Krankenhäuser? Latest update: 22 April 2015. Berlin: Gemeinsamer Bundesausschuss. https://www.g-ba.de/ institution/themenschwerpunkte/qualitaetssicherung/ qualitaetsbericht/suche/ [accessed: 10 November 2015].

GKV Spitzenverband (Hrsg.) (2008): Vereinbarung zur externen Qualitätssicherung und zum einrichtungsinternen Qualitätsmanagement in der stationären und ambulanten Rehabilitation und der stationären Vorsorge nach § 137d Absätze 1, 2 und 4 SGB V Latest update: 17 February 2014. Bonn. https://www.gkv-spitzenverband.de/ media/dokumente/krankenversicherung_1/ rehabilitation/qualitaetsmanagement/Reha_Vereinbarung__ 137d_Abs_124_Stand_20080601.pdf [accessed: 28 October 2015].

Haas H \& Mittelmeier W (2014): Die Einführung des Endo Cert-Systems zur Zertifizierung von Endoprothesenzentren: Erfahrungen aus der Pilotphase. Der Orthopäde 43(6), 534-540. DOI: 10.1007/s00132-014-2294-2.

Hassenpflug J \& Liebs TR (2014): Register als Werkzeug für mehr Endoprothesensicherheit: Erfahrungen aus anderen Ländern und dem Aufbau des Endoprothesenregisters Deutschland. Bundesgesundheitsblatt - Gesundheitsforschung - Gesundheitsschutz 57(12), 1376-1383. DOI: 10.1007/s00103-014-2057-6.

Herberts P \& Malchau H (2000): Longterm registration has improved the quality of hip replacement: a review of the Swedish THR Register comparing 160,000 cases. Acta Orthopaedica Scandinavica 7(2), 111-121.

IQTiG (2015): Herzlich Willkommen beim Institut für Qualitätssicherung und Transparenz im Gesundheitswesen! Berlin: Institut für Qualitätssicherung und Transparenz im Gesundheitswesen. http://www.iqtig.org/index [accessed: 10 November 2015].

Jeschke E, Heyde K \& Günster C (2013): Der Zusammenhang von Komplikationen im Krankenhaus und im Follow-up und Implikationen für die Qualitätsmessung bei Hüftgelenksendoprothesen - Eine Analyse von AOK-Routinedaten. Das Gesundheitswesen 75(5), 288-295. DOI: 10.1 055/s-0032-1329938.

Kärrholm J (2010): The Swedish Hip Arthroplasty Register (www.shpr.se). Acta Orthopaedica 81(1), 3-4. DOI: $10.3109 / 17453671003635918$.

Knutson K \& Robertsson O (2010): The Swedish Knee Arthroplasty Register (www.knee.se): The inside story. Acta Orthopaedica 81(1), 5-7. DOI: 10.3109/17453671003667267.
Lau RL, Perruccio AV, Gandhi R \& Mahomed N (2012): The role of surgeon volume on patient outcome in total knee arthroplasty: a systematic review of the literature. Musculoskeletal Disorders 14, 250. DOI: 10.1186/1471-2474-13250.

Liebs TR \& Hassenpflug J (2012): Qualitätssicherung. In: Deutsche Gesellschaft für Orthopädie und Unfallchirurgie e.V.: Forschung in Orthopädie und Unfallchirgurgie - Bestandsaufnahme und Ausblick. Weißbuch Forschung in Orthopädie und Unfallchirurgie. 165-166. http://www. dgu-online.de/fileadmin/published_content/4.Wissenschaft/PDF/DGOU_Weissbuch_Muskuloskelettale_ Forschung_final.pdf.

Malchau H, Garellick G, Eisler T, Kärrholm J \& Herberts P (2005): Presidential guest address: the Swedish Hip Registry: increasing the sensitivity by patient outcome data. Clinical Orthopaedics and Related Research 441, 19-29.

Mittelmeier W, Josten C, Siebert HR, Niethard FU, Marzi I \& Klüß D (2012): Forschung in Orthopädie und Unfallchirugie Bestandsaufnahme und Ausblick - Weißbuch Forschung in Orthopädie und Unfallchirugie der Deutschen Gesellschaft für Orthopädie und Unfallchirurgie. Aachen: Shaker Verlag GmbH. ISBN: 978-38440-1775-5.

QS-Reha (2015): GKV-QS-Reha ${ }^{\circledR}$-Berlin: GKV-Spitzenverband. http://www.qs-reha.de/ [accessed: 10 November 2015].

Schräder P \& Ewerbeck V (2007): Erfahrungen mit Mindestmengen in der Orthopädie. Der Chirurg 78(11), 999-1011. DOI: 10.1007/s00104-007-1411-8.

Swedish Knee Arthroplasty Register (Hrsg.) (2014): Annual Report 2014. Lund. ISBN: 978-91-980722-7-3.

vdek (2011): Knie-TEP-Transparenzliste der Verbände der Krankenkassen auf Bundesebene und des Verbandes der privaten Krankenversicherung von den Krankenkassen gemäß der Mindestmengenvereinbarung des Gemeinsamen Bundesausschusses (G-BA) akzeptierte Krankenhäuser zur Operation von Kniegelenk-Totalendoprothesen (Knie-TEP). https://www.rheuma-liga.de/fileadmin/ user_upload/Dokumente/Hilfe_bei_Rheuma/Krankheitsbilder/Arthrose/knie_tep_liste.pdf [accessed: 04 November 2015].

von Lewinski G, Floerkemeier T, Budde S, Fuhrmann U, Schwarze M, Windhagen H \& Radtke K (2015): Erfahrungen mit der Einrichtung eines zertifizierten Endoprothesenzentrums. Der Orthopäde 44(3), 193-202. DOI: 10.1007/s00132-014-3022-7.

WiDO (2007): Qualitätssicherung der stationären Versprgung mit Routinedaten (QSR): Abschlussbericht. Bonn: Wissenschaftliches Institut der AOK (Hrsg.). ISBN: 978-392209342-8.

Zenk K, Finze S, Kluess D, Bader R, Malzahn J \& Mittelmeier W (2014): Einfluss der Erfahrung des Operateurs in der Hüftendoprothetik: Abhängigkeit von Operationsdauer und Komplikationsrisiko. Der Orthopäde 43(6), 522-528. DOI: 10.1007/s00132-014-2292-4. 